\title{
Randomized Trial of a Lifestyle Intervention for Urban Low-Income African Americans with Type 2 Diabetes
}

\author{
Elizabeth B. Lynch, $P h D^{7}$, Laurin Mack, $P h D^{2}$, Elizabeth Avery, $M S^{7}$, Yamin Wang, $M S^{7}$, \\ Rebecca Dawar, $M P H^{\prime}$, DeJuran Richardson, $P h D^{l, 3}$, Kathryn Keim, $P h D, R D^{4}$, \\ Jennifer Ventrelle, MS, $R D^{7}$, Bradley M. Appelhans, $P h D^{7}$, Bettina Tahsin, MS, RD, CDE 5,6 , and \\ Leon Fogelfeld, MD 5 ,6
}

\begin{abstract}
'Department of Preventive Medicine, Rush University Medical Center, Chicago, IL, USA; ${ }^{2}$ Department of Behavioral Sciences, Rush University Medical Center, Chicago, IL, USA; ${ }^{3}$ Department of Mathematics \& Computer Science, Lake Forest College, Lake Forest, IL, USA; ${ }^{4}$ Department of Nutrition, Rush University Medical Center, Chicago, IL, USA; ${ }^{5}$ Division of Endocrinology, Department of Internal Medicine, Rush University Medical Center, Chicago, IL, USA; 'Division of Endocrinology, Department of Medicine, John H Stroger Hospital, Chicago, IL, USA.
\end{abstract}

BACKGROUND: African Americans suffer more than nonHispanic whites from type 2 diabetes, but diabetes selfmanagement education (DSME) has been less effective at improving glycemic control for African Americans. Our objective was to determine whether a novel, culturally tailored DSME intervention would result in sustained improvements in glycemic control in low-income AfricanAmerican patients of public hospital clinics.

RESEARCH DESIGN AND METHODS: This randomized controlled trial $(n=211)$ compared changes in hemoglobin Alc (A1c) at 6, 12, and 18 months between two arms: (1) Lifestyle Improvement through Food and Exercise (LIFE), a culturally tailored, 28-session community-based intervention, focused on diet and physical activity, and (2) a standard of care comparison group receiving two group DSME classes. Cluster-adjusted ANCOVA modeling was used to assess Alc changes from baseline to 6, 12, and 18 months, respectively, between arms.

RESULTS: At 6 months, Alc decreased significantly more in the intervention group than the control group $(-0.76 \mathrm{vs}$ $-0.21 \%, p=0.03)$. However, by 12 and 18 months, the difference was no longer significant (12 months -0.63 intervention vs -0.45 control, $p=0.52)$. There was a decrease in Alc over 18 months in both the intervention $(\beta=$ $-0.026, p=0.003)$ and the comparison arm $(\beta=-0.018$, $p=0.048)$ but no difference in trend $(p=0.472)$ between arms. The intervention group had greater improvements in nutrition knowledge (11.1 vs 6.0 point change, $p=$ 0.002 ) and diet quality (4.0 vs -0.5 point change, $p=$ 0.018 ) while the comparison group had more participants with improved medication adherence $(24 \%$ vs $10 \%, p<$ 0.05) at 12 months.

CONCLUSIONS: The LIFE intervention resulted in improved nutrition knowledge and diet quality and the comparison intervention resulted in improved medication adherence. LIFE participants showed greater Alc reduction than standard of care at 6 months but the difference between groups was no longer significant at 12 and 18 months.

NIH TRIAL REGISTRY NUMBER: NCT01901952

Received March 26, 2018

Revised October 12, 2018

Accepted January 22, 2019

Published online April 8, 2019
KEY WORDS: diabetes; self-management; randomized trials; disparities.

J Gen Intern Med 34(7):1174-83

DOI: $10.1007 / \mathrm{s} 11606-019-04894-\mathrm{y}$

(C) Society of General Internal Medicine 2019

$\mathrm{C}$ ompared to non-Hispanic whites, African Americans are more likely to have type 2 diabetes (T2DM), are more likely to suffer and die from diabetes-related complications, and experience higher diabetes hospitalization rates. ${ }^{1,2} \mathrm{Im}$ proved glycemic control in African Americans would result in fewer microvascular complications as well as reduced healthcare utilization and costs. ${ }^{3}$

Extensive evidence suggests that diabetes self-management education (DSME) interventions are effective at reducing hemoglobin A1 (A1c) for up to 12 months. ${ }^{4-7}$ However, a recent meta-analysis found that DSME has not been effective at reducing A1c in African Americans. ${ }^{8}$ There is limited evidence to inform effective strategies for improving longterm diabetes self-management in African Americans.

The Lifestyle Improvement through Food and Exercise (LIFE) intervention ${ }^{9}$ is an intensive, group-based DSME intervention to help low-income African Americans with uncontrolled T2DM improve glycemic control through changes to diet and physical activity. The LIFE intervention was designed using a novel cultural-tailoring strategy in which educational information about nutrition was reframed to match the preexisting beliefs of low-income African-American patients to facilitate the learning process and improve knowledge retention. ${ }^{9}$ A pilot study showed that the LIFE intervention was effective at reducing A1c at 6 months, ${ }^{10}$ and the current study tests whether the LIFE intervention can achieve sustained changes in A1c to 12 and 18 months.

The primary study aim was to examine whether the LIFE intervention resulted in greater long-term improvements in glycemic control than a comparison intervention consisting of two group classes taught by a registered dietitian (RD). We 
hypothesized that intervention participants would show a greater A1c reduction at 12 months than comparison participants and that the difference would be sustained 6 months after the conclusion of the intervention (at 18 months).

\section{RESEARCH DESIGN AND METHODS}

\section{Design and Procedures}

The LIFE study used a single-blind randomized controlled trial design comparing effectiveness of two DSME approaches to achieving sustained improvements to glycemic control among low-income African Americans with T2DM. Patients randomized to the intervention received a culturally tailored group-based DSME intervention of 28 group sessions delivered by a registered dietitian (RD) in a community setting and peer supporter phone calls over 12 months. Patients randomized to the comparison arm received two DSME sessions, delivered in the clinic, in the first 6 months of the study period. Both arms were taught the seven core DSME content areas as defined by the American Association of Diabetes Educators: healthy eating, being active, monitoring, medication, problemsolving, reducing risks, and healthy coping. ${ }^{11}$ Full assessments were conducted at baseline and 12 and 18 months and an abbreviated assessment was conducted at 6 months. Blinded research staff conducted all assessments at the patients' clinic. The primary study outcome was change in A1c at 12 months. Research staff also telephoned participants every 3 months to collect information about healthcare utilization (e.g., hospitalizations, ER visits) and update contact information. Participants received $\$ 100$ for each full assessment and $\$ 25$ for brief assessments.

\section{Participants}

Participants were recruited from five outpatient primary care community clinics that are part of the Cook County Health and Hospitals System (CCHHS) which is the public, safety-net hospital system serving residents of Cook County, Illinois. Patients were recruited in six cohorts of 30 to 40 patients each. Each cohort was recruited within a single clinic, with one clinic providing two separate cohorts. At each clinic, potentially eligible patients were identified through a medical record review, contacted and prescreened by study staff, and invited to attend a group information session at their clinic. Eligible patients provided informed consent and were randomized into intervention vs. control arms following completion of the baseline assessment. A total of 211 participants were randomized. Within each cohort, patients randomized to the intervention were assigned to the same DSME class, thereby forming a cluster among the study participants. Recruitment took place from March 2012 to April 2014 and intervention groups were conducted from August 2012 to August 2015. More details about recruitment are available elsewhere. ${ }^{12}$ The study was approved by the Rush University Medical Center and Cook
County Health and Hospitals System (CCHHS) Institutional Review Boards. All participants gave written informed consent. The trial was monitored by an independent Data and Safety Monitoring Board and prospectively registered with ClinicalTrials.gov (NCT01901952).

Inclusion criteria included uncontrolled T2DM $(\mathrm{HbAlc} \geq$ $7.0 \%$ ), African-American race, age $\geq 18$, seen at least once in the past 12 months at a CCHHS primary care clinic, and available to attend group sessions during specific hours.

Participants were excluded if they had any of the following: BMI $<18.5 \mathrm{~kg} / \mathrm{m}^{2}$, end-stage renal disease (GFR $<15 \mathrm{~mL} /$ $\min / 1.73 \mathrm{~m}^{2}$ ), history of stroke with paresis, congestive heart failure (New York Heart Association class 2-4), major endorgan T2DM complications, or any conditions limiting probable lifespan to less than 4 years, current pregnancy, diagnosis of a major psychiatric condition or impaired cognitive function, prednisone use in the prior 3 months, history of weight loss surgery, inability to walk two blocks without stopping, lack of telephone access, lack of provider clearance for study participation, and cohabitation with an active study participant.

\section{The LIFE Intervention}

The intervention was delivered in 28 group sessions over 12 months: weekly for the first 4 months, biweekly for the second 4 months, and monthly for the third 4 months. Two additional maintenance sessions were held at months 15 and 18. Sessions were held in a community setting proximate to the patients' clinic with 15-20 participants per group. The intervention had four main components: (1) culturally tailored diabetes nutrition education delivered by an RD, (2) physical activity, (3) self-monitoring of blood glucose (SMBG), and (4) social support.

An RD delivered the intervention content and an experienced African-American group facilitator and AfricanAmerican peer supporters led the social support component. Peer supporters, who were community members with T2DM, telephoned participants at the same frequency as the group sessions.

The bulk of the LIFE intervention curriculum focused on diet change, which is the most challenging diabetes selfmanagement behavior. ${ }^{13}$ Participants were encouraged to maintain consistent carbohydrate intake levels throughout the day and eat a diet consistent with the American Diabetes Association guidelines. The nutrition education curriculum was culturally tailored to match pre-existing cultural beliefs about diet and health, as described in prior studies. ${ }^{9}$ Cultural adaptations incorporated into the intervention included a culturally tailored nutrition education curriculum and use of peer supporters who were African-American women with diabetes. Tailoring of the curriculum was informed by cognitive anthropology studies with low-income African-American women that indicated (a) awareness of the impact of macronutrients but limited knowledge of macronutrient content of foods (especially carbohydrates), (b) conceptual organization of 
foods into functional categories (i.e., meals and snacks) rather than nutrient profiles, and (c) a category of natural foods (fruits and vegetables) frequently labeled "God's food." The curriculum focused on increasing declarative knowledge of macronutrient content of foods (e.g., memorizing which foods are carbohydrates) and procedural knowledge about how to construct a healthy meal or snack, using a modified version of the plate method. ${ }^{14}$ In addition, we used the concept of "God's food" to encourage consumption of whole grains. Sensitivity to literacy was reflected in use of simple teaching materials and use of interactive and hands-on teaching methods.

Each session consisted of nutrition education, a short physical activity, a healthy snack, and a group discussion about goals, progress, and barriers to behavior change. Participants also set behavioral goals for diet, physical activity, and SMBG at each session and used logs and pedometers to self-monitor those behaviors between sessions. Logs and pedometers were reviewed at group sessions and during peer supporter phone calls. RDs helped participants to individually tailor their diet in response to recorded blood glucose levels. During the group discussion, participants were guided in informal problemsolving focused on overcoming barriers to behavior change, such as social pressure to eat unhealthily and financial stressors. Social support was provided in sessions by interventionists, peer supporters, and other group members.

\section{Comparison Group}

The comparison group received the DSME content in two RDtaught group sessions in the first 6 months of the study period. Both classes were offered three times to maximize attendance and participants received reminder calls. This level of DSME is what is currently reimbursable by CMS following the first year of diagnosis and therefore constitutes standard of care.

Participants received $\$ 10$ per attended class for transportation and other costs. More intervention details are available elsewhere. ${ }^{9}$

\section{Measures}

All assessments were conducted in the patients' primary care clinic by research assistants blinded to participant treatment status. Full assessments consisted of two visits 1 week apart conducted at baseline and 12 and 18 months. All measures are described in Table 1. At the first visit, participants completed a 24-h food recall, measurement of Alc, height, weight, blood pressure, and study questionnaires and were given an accelerometer to wear for 7 days. At the second visit, participants returned the accelerometer and completed a second 24-h food recall. At each assessment, participants received their current A1c and blood pressure values along with the target ranges. A1C, weight, blood pressure, and a subset of study questionnaires were completed at 6 months. Follow-up diet and physical activity assessments were conducted at 12 and 18 months. Prescribed medication was collected by self-report and reconciled with the electronic medical record. Two antiglycemic medication scores were calculated for each participant at 12 months. The first score was a sum of the total number of units of each type of medication (sulfonylureas, insulin, and metformin), where unit is defined as the minimally effective dose, and the second was the percent of each medication's maximum daily dosage, adjusted for median absolute decrease in $\mathrm{Alc} .^{32}$

\section{Statistical Analysis}

Basic group-specific descriptive analyses were performed using means \pm SD for approximately normal continuous measures; median, first, and third quartiles for non-normal data; and frequencies and percentages for categorical measures. Each cohort was viewed as a cluster with patient as the randomization unit. The resulting intraclass correlation coefficient (ICC) was computed to assess the impact of clustering. Data analysis strategies were employed to account for the clustering study design. Differences in patient characteristics between the study arms were assessed using cluster-adjusted analysis of covariance (ANCOVA) for approximately normal data and clusteradjusted Friedman's rank ANCOVA modeling for non-normal data. For categorical data, a cluster-adjusted chi-square test was used for cell counts $\geq 5$ and Fisher's exact test was used when counts were $<5$. Cluster-adjusted ANCOVA modeling was used to assess A1c changes from baseline to 6,12, and 18 months, respectively, between arms. Mixed effects modeling with unstructured covariances was used to assess trends in A1c change over time. Models included cluster as a random effect as well as a treatment group indicator, time (since baseline), and a treatment-by-time interaction. A priori specified covariates added to this model and assessed using backwards stepwise elimination with a cut point of $p<0.20$ included age, gender, baseline A1c, diabetes duration, insulin-use, and PHQ-9 score which was found to be significantly different between arms at baseline $(p=0.03)$. In subsequent analyses, a three-way interaction term (consisting of treatment group indicator and time) was added to the mixed effects models to assess the following potential treatment moderators: age, gender, baseline A1c, health literacy, and depressive symptoms (see Table 1). Time-to-event analyses of secondary outcomes were performed using cluster-adjusted logrank tests. All statistical tests were two-sided with a $p$ value of $<0.05$ and performed using SAS software (SAS Institute Inc. SAS 9.4 Help and Documentation. Cary, NC: SAS Institute Inc., 2011).

\section{RESULTS}

\section{Recruitment and Attrition}

As indicated in the CONSORT diagram (Fig. 1), the research team screened 822 of 3048 patients with T2DM from participating clinics. Of those, 211 were randomized and the primary outcome (A1c) was collected from the following number of participants at the three follow-up visits: 198 (94\%) at 
Table 1 List of Measures

\begin{tabular}{|c|c|}
\hline Variable & Measure \\
\hline $\begin{array}{l}\text { Participant demographic } \\
\text { information }\end{array}$ & Self-reported demographic questionnaires including questions about income, education, employment, and insurance. \\
\hline Glycemic control & $\begin{array}{l}\text { Hemoglobin A1c levels. Blood samples were collected via finger stick and processed through the Afinion AS100 } \\
\text { Hemoglobin A1C Analyzer System. }\end{array}$ \\
\hline Blood pressure & $\begin{array}{l}\text { Blood pressure was measured by research staff using Omron Digital Blood Pressure Monitor (Omron Healthcare, Inc. } \\
\text { Lake Forest, Illinois). Final value was average of three readings taken } 2 \text { min apart while participant was seated. }\end{array}$ \\
\hline Body mass index & $\begin{array}{l}\text { Weight was measured using a balance beam digital scale (Health } O \text { Meter), reported to } 1 / 10 \mathrm{~kg} \text { ( } 5 \text { min). Height } \\
\text { was measured using wall mounted stadiometer. BMI was calculated by dividing weight (kilograms) by height (meters } \\
\text { squared). }\end{array}$ \\
\hline Medications & $\begin{array}{l}\text { Participants brought all medications to assessment visit and RA recorded medication and dosage. Congruence } \\
\text { between self-reported medications and pharmacy records for low-income adults }=91 \% \text { for major drug classes. }{ }^{16} \\
\text { Diabetes medications were also confirmed via chart review. }\end{array}$ \\
\hline Medical history & $\begin{array}{l}\text { Self-reported participant medical history information such as duration diabetes age of onset, number of diabetic } \\
\text { complications, and comorbidities, ER visits in past } 6 \text { months, etc. }\end{array}$ \\
\hline Diet & $\begin{array}{l}\text { Dietary intake was measured using the Nutrition Data System for Research 24-Hour Dietary Recall (NDSR; Nutrition } \\
\text { Coordinating Center, University of Minnesota), a computer-based software application that facilitates the collection of } \\
\text { standardized dietary recalls using a multiple-pass interview approach. }\end{array}$ \\
\hline $\begin{array}{l}\text { Alternative Healthy } \\
\text { Eating Index (AHEI) }\end{array}$ & $\begin{array}{l}\text { Alternative Healthy Eating Index } 2010 \text { (AHEI) }{ }^{17} \text { is associated with reduced cancer, CVD, and all-cause mortality. It is } \\
\text { comprised of } 11 \text { subscales ranging from } 1 \text { to } 10 \text { for a total range of } 0-110 \text {. }\end{array}$ \\
\hline Physical activity & $\begin{array}{l}\text { Mean weekly minutes of moderate level activity, daily steps, and sedentary time were measured with the Actigraph } \\
\text { GT3X, a tri-axial accelerometer measuring acceleration in three axes (vertical, anteroposterior, mediolateral) and step } \\
\text { count. Classifications of daily light, moderate, vigorous, very vigorous physical activity minutes, and minutes in } \\
\text { sedentary behavior were determined based on previously published thresholds. } 18 \text {, 19 The accelerometer data were } \\
\text { scored using PC-SAS (SAS Institute Inc., Cary, NC) version 9.2, partly using sample codes from NHANES } \\
\text { accelerometer data analysis (http://riskfactor.cancer.gov/tools/nhanes pam). }\end{array}$ \\
\hline Nutrition knowledge & $\begin{array}{l}\text { An adapted version of the Nutrition Knowledge Questionnaire }{ }^{20,21} \text { and the AdultCarbQuiz } 62 \text { items with response } \\
\text { format: yes, no, I do not know. Score range 0-62. Higher scores indicate greater nutrition knowledge. }\end{array}$ \\
\hline Medication Adherence & $\begin{array}{l}\text { Morisky Medication Adherence Scale (MMAS)-8, } 8 \text {-item self-report measure: MMAS- } 8 \text { score }<6 \text { signifies low } \\
\text { medication adherence. }\end{array}$ \\
\hline Depression & $\begin{array}{l}\text { The Patient Health Questionnaire (PHQ-9 })^{27} \text { has nine items with a response format from } 0 \text { to } 3 \text { (Not at all to nearly } \\
\text { every day). Higher scores indicate greater depression severity. Scores range from } 0 \text { to } 27 \text {. Score } \geq 10 \text { suggests } \\
\text { moderate or severe depression. }\end{array}$ \\
\hline Perceived social support & $\begin{array}{l}\text { The Support Received subscale from Diabetes Care Profile }{ }^{28-30} \text { is } 6 \text { items with a response format ranging from } 1 \text { to } 5 \\
\text { (strongly disagree to strongly agree). Higher scores indicate more social support. }\end{array}$ \\
\hline $\begin{array}{l}\text { Diabetes-specific quality of } \\
\text { life }\end{array}$ & $\begin{array}{l}\text { The Social and Personal Factors subscale from Diabetes Care Profile } \\
\text { from } 1 \text { to } 5 \text { (strongly disagree to strongly agree). Lower scores indicate higher quality of life. }\end{array}$ \\
\hline Self-efficacy & $\begin{array}{l}\text { The Self-care ability subscale from Diabetes Care Profile }{ }^{28-30} \text { has } 4 \text { items and a response format ranging from } 1 \text { to } 5 \\
\text { (strongly disagree to strongly agree). Higher scores indicate greater self-efficacy. }\end{array}$ \\
\hline Health literacy & $\begin{array}{l}\text { The Newest Vital Sign (NVS) }{ }^{3 P} \text { has } 6 \text { items with a yes-no response format and higher scores indicate greater health } \\
\text { literacy. Limited health literacy is defined as a score of } 0-1 \text {. }\end{array}$ \\
\hline
\end{tabular}

6 months, 196 (93\%) at 12 months, and 190 (90\%) at 18 months. By study end, 4 patients had died and 13 patients were lost to follow-up (6\%). There were no study-related adverse events.

\section{Patient Characteristics}

Participants had a mean age of 55, most were uninsured at baseline $(65 \%)$ and $43 \%$ reported an annual household income below the federally defined poverty level. Participants had been diagnosed with diabetes for a mean of 9.4 years, $45.5 \%$ were taking insulin and $28.4 \%$ screened positive for depression. Baseline characteristics appear in Table 2. No statistically significant differences were found between the groups at baseline except a between-group difference in the median PHQ-9 score (7.0 vs. 5.0, $p=0.03)$.

\section{Changes in HbAlc}

Figure 2 displays the marginal means and standard errors for A1c change at each time point. The mean change from baseline to 12 months, the primary endpoint, was not significantly different between arms ( $p=0.52$, see Table 3$)$. At 6 months, A1c decreased significantly more in the intervention than in the comparison group (intervention mean 6-month change =$0.76, \mathrm{SD}=1.70$; control mean 6 -month change $=-0.21, \mathrm{SD}=$ $1.74 ; p=0.03)$, but by 12 and 18 months, the difference was no longer significant (Table 3 ). Mixed effects modeling over all four time points $(0,6,12,18$ months) showed a statistically significant A1c decrease over 18 months in the intervention group $(\beta=-0.026, p=0.003)$ and a significant, but lesser, decrease in the comparison group $(\beta=-0.018, p=0.048)$. There was no difference in trend $(p=0.47)$ between arms. No intervention moderators were detected.

\section{Changes in Secondary Outcomes}

Table 3 shows changes in secondary outcome variables from baseline to 12 and 18 months (diet and PA were not collected at 6 months). Nutrition knowledge improved more in the intervention vs. comparison group at 12 months (11.1 vs 6.0 point change, $p=0.002, d=1.46$ ) but the difference was only marginally significant at 18 months $(p=0.06)$. Similarly, diet quality (AHEI) improved more in the intervention vs comparison group at 12 months ( $4.0 \mathrm{vs}-0.5$ point change, $p=0.018$, $d=1.27)$. This difference was not maintained at 18 months. The proportion of individuals who improved their medication 


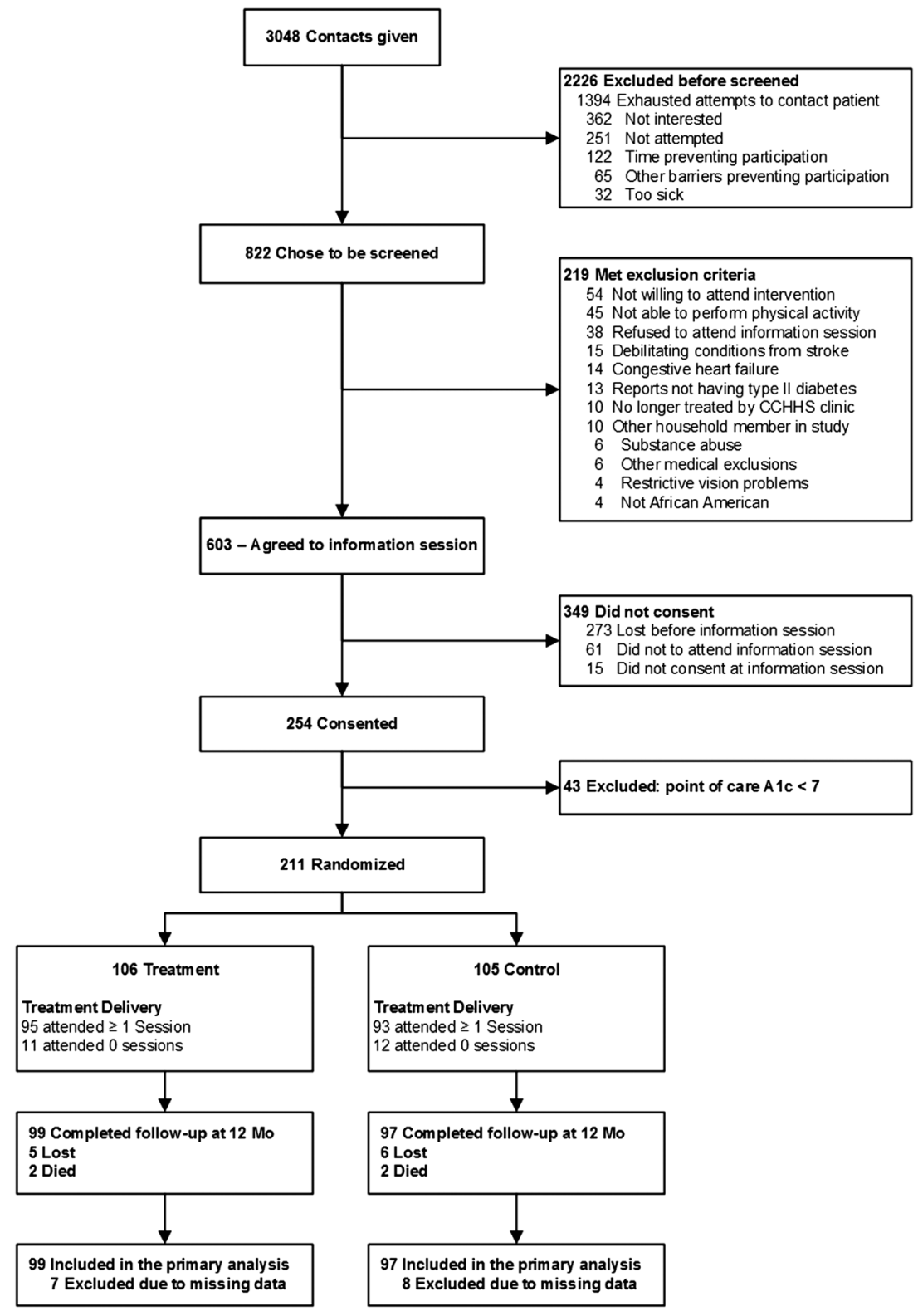

Figure 1 Participant flow diagram.

adherence from baseline was greater in the comparison group than the intervention group at 12 months (24\% vs $10 \%$, $p=.021$ ) but not 18 months. There was no difference between groups in changes to physical activity, emergency room or hospital utilization, or antiglycemic medication scores (change in total units score, $p=0.26$; change in adjusted dosage score, $p=0.71)$.

\section{Process Measures}

The average number of group sessions attended by intervention participants was 13.8 out of a possible $28 ; 51 \%$ attended at least $60 \%$ of sessions and $25 \%$ attended at least $80 \%$ of sessions. At least half of the planned peer supporter phone calls were completed by a majority (73\%) of participants. The percent of intervention classes attended in the first 6 months was associated with 6-month A1c change ( $r=-0.31, p=0.002$ ), but neither 12- nor 6-month attendance was associated with 12-month A1c change. Intervention participants brought their pedometers to $76.7 \%$ of attended sessions and brought their food logs to $41 \%$ of attended sessions.

A majority $(68.6 \%)$ of control participants attended both classes, $20 \%$ attended one class, and $11 \%$ attended no classes. The percent of control group classes attended was associated with 12-month HbA1c change $(r=-0.21, p=0.04)$.

\section{CONCLUSIONS}

The current study tested the hypothesis that the LIFE intervention would result in greater improvements to 
Table 2 Participant Characteristics at Baseline

\begin{tabular}{|c|c|c|c|}
\hline Characteristics & Total $(N=211)$ & Comparison $(N=105)$ & Treatment $(N=106)$ \\
\hline \multicolumn{4}{|l|}{ Demographics } \\
\hline Age, mean (SD) & $55.0(10.3)$ & $54.8(9.0)$ & $55.1(11.5)$ \\
\hline Female, $n(\%)$ & $148(70.1)$ & $73(69.5)$ & $75(70.8)$ \\
\hline \multicolumn{4}{|l|}{ Education, $n(\%)$} \\
\hline Less than high school & $28(13.3)$ & $17(16.2)$ & $11(10.4)$ \\
\hline High school & $69(32.7)$ & $35(33.3)$ & $34(32.1)$ \\
\hline Some college/technical school & $87(41.2)$ & $40(38.1)$ & $47(44.3)$ \\
\hline$\geq$ College degree & $27(12.8)$ & 13 (12.4) & $14(13.2)$ \\
\hline \multicolumn{4}{|l|}{ Relationship status, $n(\%)$} \\
\hline Single & $109(51.7)$ & $50(47.6)$ & $59(55.7)$ \\
\hline Lives with partner/spouse & $50(23.7)$ & $29(27.6)$ & $21(19.8)$ \\
\hline Lives separately from partner/spouse & $14(6.6)$ & $7(6.7)$ & $7(6.6)$ \\
\hline Divorced & $21(10.0)$ & 12 (11.4) & $9(8.5)$ \\
\hline Widowed & $17(8.1)$ & $7(6.7)$ & $10(9.4)$ \\
\hline \multicolumn{4}{|l|}{ Annual income ${ }^{\mathrm{a}}, n(\%)$} \\
\hline$<\$ 9999$ & $68(32.2)$ & $29(27.6)$ & $39(36.8)$ \\
\hline$\$ 10,000-\$ 19,999$ & $67(31.8)$ & $39(37.1)$ & $28(26.4)$ \\
\hline$\$ 20,000-\$ 39,999$ & $56(26.5)$ & $26(24.8)$ & $30(28.3)$ \\
\hline$>\$ 40,000$ & $11(5.2)$ & $6(5.7)$ & $5(4.7)$ \\
\hline Refused/do not know & $9(4.3)$ & $5(4.8)$ & $4(3.8)$ \\
\hline Below poverty ratio, $n(\%)$ & $87(43.1)$ & $39(39.0)$ & $48(47.1)$ \\
\hline \multicolumn{4}{|l|}{ Insurance, $n(\%)$} \\
\hline Uninsured & $138(65.4)$ & $71(67.6)$ & $67(63.2)$ \\
\hline Medicare only & $29(13.7)$ & $13(12.4)$ & $16(15.1)$ \\
\hline Medicaid only & $24(11.4)$ & 12 (11.4) & $12(11.3)$ \\
\hline Medicare plus Medicaid & $8(3.8)$ & $2(1.9)$ & $6(5.7)$ \\
\hline Private & $8(3.8)$ & $5(4.8)$ & $3(2.8)$ \\
\hline Other & 4 (1.9) & $2(1.9)$ & $2(1.9)$ \\
\hline \multicolumn{4}{|l|}{ Employment, $n(\%)$} \\
\hline Full-time employment & 25 (11.9) & $16(15.2)$ & $9(8.5)$ \\
\hline Part-time employment & $26(12.3)$ & 12 (11.4) & $14(13.2)$ \\
\hline Unemployed & $72(34.1)$ & $38(36.2)$ & $34(32.1)$ \\
\hline Retired & $48(22.8)$ & $20(19.1)$ & $28(26.4)$ \\
\hline Too ill to work & $27(12.8)$ & $9(8.6)$ & $18(17.0)$ \\
\hline Other/refused & $13(6.2)$ & $10(9.5)$ & $3(2.8)$ \\
\hline \multicolumn{4}{|l|}{ Medical factors } \\
\hline \multirow{2}{*}{\multicolumn{4}{|c|}{ Diabetic medications, $n(\%)$}} \\
\hline & & & \\
\hline Insulin ${ }^{\mathrm{b}}$ & $96(45.5)$ & $51(48.6)$ & $45(42.5)$ \\
\hline Oral agent only & $111(52.6)$ & $53(50.5)$ & $58(54.7)$ \\
\hline Diet control only & $4(1.9)$ & $1(1.0)$ & $3(2.8)$ \\
\hline \multicolumn{4}{|l|}{ Diabetes comorbidities, $n(\%)$} \\
\hline Heart disease & $10(4.7)$ & $6(5.7)$ & $4(3.8)$ \\
\hline Hypertension ${ }^{\mathrm{c}}$ & $192(91.0)$ & $94(89.5)$ & $98(92.5)$ \\
\hline \multicolumn{4}{|l|}{ Total number of diabetes comorbidities ${ }^{\mathrm{d}}, n(\%)$} \\
\hline 0 & $15(7.1)$ & $6(5.7)$ & $9(8.5)$ \\
\hline $1-2$ & $101(47.9)$ & $46(43.8)$ & $55(51.9)$ \\
\hline$\geq 3$ & $95(45.0)$ & $53(50.5)$ & $42(39.6)$ \\
\hline Other comorbidities ${ }^{\mathrm{e}, \mathrm{f}}, n(\%)$ & & & \\
\hline 0 & $82(38.9)$ & $40(38.1)$ & $42(39.6)$ \\
\hline $1-2$ & $108(51.2)$ & $56(53.3)$ & $52(49.1)$ \\
\hline$\geq 3$ & $21(10.0)$ & $9(8.6)$ & $12(11.3)$ \\
\hline Hemoglobin A1c (\%), median (q1, q3) & $8.5(7.8,9.8)$ & $8.4(7.6,9.7)$ & $8.6(7.8,9.9)$ \\
\hline Hemoglobin A1c $>9 \%, n(\%)$ & $80(37.9)$ & $42(40.0)$ & $38(35.9)$ \\
\hline Body mass index, median (q1, q3) & $34.7(29.3,40.2)$ & $34.8(29.3,40.5)$ & $34.6(29.3,39.9)$ \\
\hline Systolic blood pressure $(\mathrm{mmHg})$, median $(\mathrm{q} 1, \mathrm{q} 3)$ & $130.5(120.5,143.5)$ & $130.5(120.5,144.5)$ & $130.5(120.5,142.5)$ \\
\hline Diastolic blood pressure (mmHg), median (q1, q3) & $81.0(74.0,87.0)$ & $81.5(75.0,88.0)$ & $79.3(73.5,88.5)$ \\
\hline Health knowledge factors & & & \\
\hline Nutrition knowledge ${ }^{\mathrm{g}}$, median $(\mathrm{q} 1, \mathrm{q} 3)$ & $35(27,40)$ & $35(27,39)$ & $34(26,40)$ \\
\hline Low health literacy,$n(\%)$ & $83(39.3)$ & $39(37.1)$ & $44(41.5)$ \\
\hline Behavioral factors & & & \\
\hline Daily dietary intake, median $(\mathrm{q} 1, \mathrm{q} 3)$ & & & \\
\hline Total kcal & $1749(1335,2236)$ & $1714(1297,2176)$ & $1769(1398,2329)$ \\
\hline Total vegetable servings & $0.6(0.3,0.9)$ & $0.6(0.3,0.9)$ & $0.6(0.3,0.9)$ \\
\hline Non-starchy vegetables (excluding potatoes, corn, legumes, peas) & $0.1(0.0,0.2)$ & $0.1(0.0,0.2)$ & $0.1(0.0,0.2)$ \\
\hline Percent kcal from carbohydrate, mean (SD) & $45.5(8.8)$ & $45.8(8.3)$ & $45.1(9.2)$ \\
\hline Percent kcal from protein & $17.0(14.0,19.6)$ & $17.3(14.3,19.9)$ & $16.8(14.0,19.6)$ \\
\hline Percent kcal from fiber & $7.9(5.8,10.6)$ & $8.0(5.8,10.8)$ & $7.6(6.0,10.0)$ \\
\hline Alternative Healthy Eating Index, mean (SD) & $48.8(10.7)$ & $50.4(11.2)$ & $47.2(10.0)$ \\
\hline Physical activity & & & \\
\hline Daily average steps, median $(\mathrm{q} 1, \mathrm{q} 3)$ & $3614(2468,4984)$ & $3819(2705,5205)$ & $3548(2366,4761)$ \\
\hline Weekly moderate intensity activity (min), mean (SD) & $38.7(92.0)$ & $37.7(73.7)$ & $39.6(107.6)$ \\
\hline Daily sedentary minutes, mean (SD) & $516.1(96.0)$ & $507.9(93.8)$ & $524.3(97.9)$ \\
\hline Low medication adherence at baseline ${ }^{\mathrm{i}}, n(\%)$ & $77(36.5)$ & $41(39.1)$ & $36(34.0)$ \\
\hline
\end{tabular}


Table 2. (continued)

\begin{tabular}{|c|c|c|c|}
\hline Characteristics & Total $(N=211)$ & Comparison $(N=105)$ & Treatment $(N=106)$ \\
\hline \multicolumn{4}{|l|}{ Psychosocial } \\
\hline PHQ-9 score', median (q1, q3) & $6.0(2.0,10.0)$ & $7.0(3.0,12.0)$ & $5.0(1.0,9.0)$ \\
\hline Moderate or severe depression (PHQ-9 $\geq 10),{ }^{\mathrm{k}} n(\%)$ & $60(28.4)$ & $37(35.2)$ & $23(21.7)$ \\
\hline Diabetes-specific social support ${ }^{1}$, median $(\mathrm{q} 1, \mathrm{q} 3)$ & $3.0(1.7,4.0)$ & $3.0(2.0,4.0)$ & $2.9(1.2,4.0)$ \\
\hline Diabetes-specific quality of life ${ }^{\mathrm{m}}$, median $(\mathrm{q} 1, \mathrm{q} 3)$ & $2.4(2.0,3.0)$ & $2.4(2.0,3.1)$ & $2.4(2.0,2.9)$ \\
\hline Diabetes-specific self-efficacy ${ }^{\mathrm{n}}$, median $(\mathrm{q} 1, \mathrm{q} 3)$ & $3.0(2.3,3.5)$ & $3.0(2.3,3.5)$ & $2.8(2.3,3.5)$ \\
\hline
\end{tabular}

Friedman's rank ANCOVA with adjustment of clinical site used for comparing non-normal data, chi-square used for categorical data, ANCOVA with adjustment of clinical site used for normally distributed continuous data

${ }^{a}$ Total family annual income before taxes

${ }^{b}$ Participant uses insulin only or insulin plus oral medication for diabetes management

${ }^{c}$ Self-reported hypertension, $>140(\mathrm{~s}) / \mathrm{or}>90(\mathrm{~d}) \mathrm{mmHg}$, or currently talking blood pressure lowering medications

${ }^{d}$ Diabetic complications and comorbidities include history of hypertension, dialysis, heart attack or myocardial infarction, heart failure, stroke, renal insufficiency, dialysis, diabetes-related eye damage, 4+ hypoglycemic incidents per month

${ }^{e}$ History of cancer, arthritis, lung, cirrhosis or liver disease, depression, asthma, sleep apnea, neurological diseases, HIV or AIDs, serious mental illness ${ }^{f}$ Although the two groups have equal medians, Wilcoxon test showing statistically significant gender differences because the ranges differ between men and women with women reaching a higher number of chronic conditions

${ }^{g}$ Nutrition Knowledge Questionnaire, 46 items, response format: yes, no, I do not know. Score range 0-46. Higher scores indicate greater nutrition knowledge

${ }^{h}$ Health literacy measured by the Newest Vital Sign, 6 items, yes-no response format, higher scores indicate greater health literacy, limited health literacy is defined as a score of $0-1$

${ }^{i}$ Morisky Medication Adherence Scale (MMAS)-8; use of the CMMAS is protected by US copyright laws. Permission for use is required. A license agreement is available from Donald E. Morisky, MMAS Research, LLC 14725 NE 20th St., Bellevue, WA, 98007

${ }^{j}$ Patient Health Questionnaire-9, 9 items, response format: range 0-3 (not at all to nearly every day). Higher scores indicate greater depression severity. Score range $0-27$

${ }^{k} P H Q-9$ score $\geq 10$

${ }^{l}$ Support attitudes subscale from Diabetes Care Profile, 6 items, response format: range 1-5 (strongly disagree to strongly agree). Higher scores indicate more social support

${ }^{m}$ Social and personal factors subscale from Diabetes Care Profile, 13 items, response format: range 1-5 (strongly disagree to strongly agree). Lower scores indicate higher quality of life

${ }^{n}$ Self-care ability subscale from Diabetes Care Profile, 4 items, response format: range 1-5 (strongly disagree to strongly agree). Higher scores indicate greater self-efficacy

glycemic control than standard of care DSME. Intervention participants achieved significant $\mathrm{A} 1 \mathrm{c}$ reductions at 6 months that were largely sustained at 12 and 18 months. A1c also decreased in the comparison group from baseline to 6,12 , and 18 months. While the A1c change was greater in the intervention group than the comparison group at each follow-up assessment, the difference between arms was only statistically significant at 6 months.

Recent meta-analyses of DSME interventions across a range of populations have reported mean A1c changes ranging from -0.16 to -0.53 at 6 months and -0.14 to

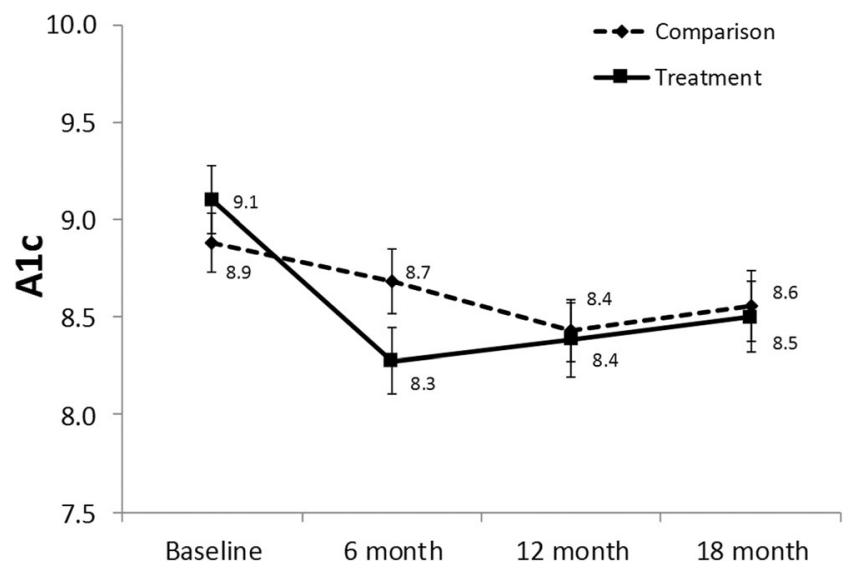

Figure 2 Means and $95 \%$ confidence intervals for HbA1c at baseline and 6,12 , and 18 months.
-0.46 at $12-14$ months. $^{4-7}$ The magnitude of the A1c change achieved by the LIFE intervention is consistent with DSME intervention effects reported by those metaanalyses, but greater than the non-significant A1c change of -0.08 reported by a meta-analysis of DSME interventions targeting African Americans. ${ }^{8}$ The current study was not powered to detect the effect size observed by this study at 12 months $(-0.18)$. LIFE is a resource-intensive intervention which requires extensive time and commitment from participants. To justify the cost of the intervention, we felt it should result in at least a clinically significant reduction in A1c $(\geq-0.5){ }^{33}$

We did not include an untreated arm in this study because we wanted to measure the LIFE intervention against standard of care, rather than usual care. Because there was no untreated arm in this study, we cannot identify with full assurance what contributed to the Alc reduction experienced by the comparison arm. This study was conducted during a time of great change in the healthcare system, both nationally and at CCHHS. The Affordable Care Act (ACA) Medicaid expansion was implemented for Cook County adults in January of 2014, which was prior to the 12-month follow-up for approximately half of study participants. Simultaneously, some of the CCHHS community clinics were experimenting with patient-centered medical home models and group visits for diabetes. It is possible that those system-level changes, which were intended to increase access to care, were 
Table 3 Changes in Secondary Outcome Variables from Baseline to 12 and 18 Months*

\begin{tabular}{|c|c|c|c|c|}
\hline \multirow[t]{3}{*}{ Outcomes } & \multicolumn{2}{|c|}{ Change at 12 months } & \multicolumn{2}{|c|}{ Change at 18 months } \\
\hline & \multirow{2}{*}{$\begin{array}{l}\text { Comparison } \\
N=99\end{array}$} & \multirow{2}{*}{$\begin{array}{l}\text { Treatment } \\
N=97\end{array}$} & \multirow{2}{*}{$\begin{array}{l}\text { Comparison } \\
N=96\end{array}$} & \multirow{2}{*}{$\begin{array}{l}\text { Treatment } \\
N=94\end{array}$} \\
\hline & & & & \\
\hline \multicolumn{5}{|l|}{ Medical outcomes } \\
\hline Hemoglobin A1c (\%), mean (SD) & $-0.45(1.68)$ & $-0.63(1.83)$ & $-0.33(1.75)$ & $-0.58(1.96)$ \\
\hline Body mass index, median $(\mathrm{q} 1, \mathrm{q} 3)$ & $-0.2(-2.1,0.8)$ & $-0.7(-2.2,0.7)$ & $-0.8(-2.4,0.8)$ & $-0.5(-2.1,1.0)$ \\
\hline Systolic blood pressure (mmHg), mean (SD) & $-0.1(19.1)$ & $-0.9(19.1)$ & $-3.9(19.2)$ & $1.7(16.8)^{\dagger}$ \\
\hline Diastolic blood pressure $(\mathrm{mmHg})$, mean (SD) & $0.6(13.3)$ & $-0.3(13.1)$ & $-0.7(12.6)$ & $0.0(11.8)$ \\
\hline \multicolumn{5}{|l|}{ Health knowledge outcomes } \\
\hline Nutrition knowledge, mean (SD) & $6.0(11.8)$ & $11.1(12.9)^{\ddagger}$ & $4.5(10.0)$ & $7.7(12.7)$ \\
\hline \multicolumn{5}{|l|}{ Behavioral outcomes } \\
\hline \multicolumn{5}{|l|}{ Daily dietary intake } \\
\hline Total kcal, median $(\mathrm{q} 1, \mathrm{q} 3)$ & $-184(-548,214)$ & $-288(-754,-32)$ & $-66(-484,190)$ & $-360(-773,184)$ \\
\hline Total vegetable servings (c), median (q1, q3) & $0.1(-0.4,0.3)$ & $0.1(-0.3,0.4)$ & $0.0(-0.3,0.4)$ & $0.0(-0.2,0.4)$ \\
\hline $\begin{array}{l}\text { Non-starchy vegetables (excluding potatoes, corn, } \\
\text { legumes, peas) (c), median }(\mathrm{q} 1, \mathrm{q} 3)\end{array}$ & $0.0(-0.1,0.1)$ & $0.0(-0.1,0.3)$ & $-0.0(-0.2,0.2)$ & $0.0(-0.1,0.1)$ \\
\hline Percent kcal from carbohydrate, median $(\mathrm{q} 1, \mathrm{q} 3)$ & $-0.4(-9.1,5.8)$ & $-1.9(-7.8,6.4)$ & $-0.8(-10.7,5.2)$ & $0.3(-7.8,7.4)$ \\
\hline Percent kcal from protein, median $(\mathrm{q} 1, \mathrm{q} 3)$ & $0.7(-2.0,4.0)$ & $2.1(-2.1,5.7)$ & $0.1(-2.4,5.1)$ & $2.1(-1.8,6.3)$ \\
\hline Percent kcal from fiber, median (q1, q3) & $0.2(-2.4,3.1)$ & $0.6(-1.7,3.3)$ & $-0.4(-2.3,2.8)$ & $0.8(-1.7,3.6)$ \\
\hline Alternative Healthy Eating Index, mean (SD) & $-0.5(13.1)$ & $4.0(12.0)^{\dagger}$ & $0.3(12.9)$ & $2.8(13.3)$ \\
\hline \multicolumn{5}{|l|}{ Physical activity } \\
\hline Average daily steps/week, median $(\mathrm{q} 1, \mathrm{q} 3)$ & $309(-327,1009)$ & $93(-481,1025)$ & $-373(943,508)$ & $-215(-909,629)$ \\
\hline $\begin{array}{l}\text { Weekly moderate intensity activity (min), } \\
\text { median (q1, } 3 \text { ) }\end{array}$ & $0.0(-14.0,10.0)$ & $0.0(-15.5,0.0)$ & $0.0(-9.0,9.0)$ & $0.0(-10.0,0.0)$ \\
\hline Daily sedentary minutes, mean (SD) & $31.9(95.2)$ & $38.1(111.0)$ & $33.4(85.1)$ & $69.3(105.6)^{\dagger}$ \\
\hline \multicolumn{5}{|l|}{ Medication adherence, $n(\%)^{\mathrm{a}}$} \\
\hline Low to high & $24(24.0)$ & $10(10.1)^{\dagger}$ & $20(21.1)$ & $14(14.4)$ \\
\hline Stayed the same & $61(61.0)$ & $74(74.8)^{\dagger}$ & $62(65.3)$ & $65(67.0)$ \\
\hline High to low & $15(15.0)$ & $15(15.2)^{\dagger}$ & $13(13.7)$ & $18(18.6)$ \\
\hline \multicolumn{5}{|l|}{ Psychosocial outcomes } \\
\hline Depression symptoms, mean (SD) & $-3.6(5.5)$ & $-1.5(6.2)^{\dagger}$ & $-2.0(6.1)$ & $-1.7(5.3)$ \\
\hline Diabetes-specific social support, mean (SD) & $0.5(1.7)$ & $0.3(1.8)$ & $0.2(1.6)$ & $0.3(1.6)$ \\
\hline Diabetes-specific quality of life, mean (SD) & $-0.1(0.9)$ & $0.0(0.9)$ & $-0.2(0.9)$ & $-0.2(0.8)$ \\
\hline Diabetes-specific self-efficacy, mean (SD) & $0.4(1.0)$ & $0.5(1.0)$ & $0.5(1.1)$ & $0.6(1.0)$ \\
\hline
\end{tabular}

*Friendman's rank ANCOVA with adjustment of clinical site used for comparing non-normal data, Mantel_Haenszel test used for categorical data, ANCOVA with adjustment of clinical site used for normally distributed continuous data

${ }^{*} p$ value $<0.05$

${ }^{a}$ MMAS-8; Use of the CMMAS is protected by US copyright laws. Permission for use is required. A license agreement is available from Donald E. Morisky, MMAS Research, LLC 14725 NE 20th St., Bellevue, WA, 98007

responsible for improved glycemic control in both intervention groups. However, some evidence supports that the improved glycemic control in the comparison group resulted from the DSME classes. The majority (89\%) of comparison arm participants attended at least one DSME class, and individuals who attended more classes achieved better glycemic control. In addition, comparison arm participants, but not intervention participants, improved medication adherence at 12 months. These findings add to evidence that all patients should receive standard of care DSME. $^{34}$

At 12 months, the intervention group showed an increase in nutrition knowledge as well as an increase in diet quality. Both interventions addressed diet and medication adherence but the LIFE intervention placed disproportionately more emphasis on diet. The attention directed toward diet among LIFE participants may have resulted in a decreased focus on medication adherence. For intervention participants, a key motivation for improving diet was to reduce diabetes medications. Unlike comparison participants, they may have viewed diet and medication as alternative strategies for improving glycemic control.
The advantage of using diet to improve glycemic control is that a healthy diet has a cascade of health benefits. While the amount of improvement in diet quality achieved by LIFE intervention participants was not associated with statistically significant changes to weight and blood pressure in the current study, the magnitude of increase on the AHEI achieved by LIFE participants in this trial at 12 months $(\sim 8 \%$ increase from baseline) has been associated with reduced risk of diabetes and cardiovascular disease in large, observational studies. ${ }^{17,35-38}$ However, the improvement to diet observed at 12 months was not sustained at 18 months.

Changing diet and physical activity may be especially challenging for low-income patients, such as those in the current study. Evidence suggests that neighborhood deprivation is related to a number of cardiometabolic risk factors, including diabetes prevalence and higher A1c. ${ }^{39-}$ ${ }^{41}$ Conditions in impoverished neighborhoods, such as high levels of food insecurity, few safe areas to engage in physical activity, and high stress associated with poverty and violence, may have made it difficult for LIFE participants to attend intervention sessions and/or achieve and sustain the diet and activity changes targeted by the 
intervention. DSME interventions may need to address environmental and social factors that influence behavior change in order to achieve sustained health benefits, particularly for low-income populations. In the short term, a brief intervention focused on medication adherence may be a resource-efficient strategy by which to achieve improved glycemic control among low-income African Americans.

One study limitation is that we did not measure diet and physical activity at 6 months, so we cannot be certain that the difference between the arms at 6 months was related to differences in diet and physical activity behavior. Another limitation is that our measure of diet was self-report and therefore potentially subject to bias. Also, we conducted only two dietary recalls per participant and did not always measure a weekend day and weekday as recommended.

In sum, the current study found that low-income AfricanAmerican participants in a novel, culturally tailored and literacy sensitive, intensive DSME intervention achieved sustained improvements in glycemic control, but did not perform meaningfully better than those receiving two DSME sessions. Findings from this study underscore the urgent need for research to discover effective behavior change interventions for improving long-term glycemic control within this patient population

Acknowledgments: Joellen Wilbur, $P h D$, and Don Waddell, MA, provided assistance with an early phase of this project. Tangula Jefferson, Candace Nicks, and Syed Quadri provided assistance with data collection. Wil Mims and Denise Mason served as peer supporters. Don Waddell, Francine Stark, Sheila Reed, and LaDawne Jenkins served as group facilitators. Jadwiga Miernik, MD, and Rajeev Mehrotra, MD, directed the patient screening for recruitment.

Corresponding Author: Elizabeth B. Lynch, PhD; Department of Preventive Medicine, Rush University Medical Center, 1700 West Van Buren, Suite 470, Chicago, IL 60625, USA (e-mail: Elizabeth lynch@rush.edu).

Author Contributions E.B.L., principal investigator, developed the study concept, directed study operations, drafted the manuscript, integrated coauthor comments and edits, and is the guarantor of this work and, as such, had full access to all the data in the study and takes responsibility for the integrity of the data and the accuracy of the data analysis. L.M. provided clinical supervision of study interventionists, led study operations, and contributed to the manuscript, particularly the methods section and tables. R.D. assisted with development of the intervention and served as project director, D.R. contributed to study design and supervised statistical analysis, and E.A. led data management and contributed to statistical analysis and study design. Y.W. conducted most statistical analyses, wrote the statistics section, and contributed to the RESULTS section. K.K. contributed to intervention design and supervised dietary data collection and performed quality control on dietary data, J.V. contributed to development and implementation of the intervention, B.A. provided clinical supervision of study interventionists and contributed to study design and editing the manuscript, B.T. assisted with study design and delivery of the intervention, and L.F. contributed to study design, manuscript and provided medical supervision for the study. Use of the $\odot$ MMAS is protected by US copyright laws. Permission for use is required. A license agreement is available from Donald E. Morisky, MMAS Research, LLC 14725 NE 20th St., Bellevue, WA, 98007.
Funding Information This research was supported by the National Institute of Diabetes and Digestive and Kidney Diseases of the National Institutes of Health under award number RO1DK092271 and the National Institute for Heart Lung and Blood (NHLBI), grant number 1P5OHL105189-01.

\section{Compliance with Ethical Standards:}

The study was approved by the Rush University Medical Center and Cook County Health and Hospitals System (CCHHS) Institutional Review Boards. All participants gave written informed consent.

Conflict of Interest: The authors declare that they do not have a conflict of interest.

Disclaimer: The content is solely the responsibility of the authors and does not necessarily represent the official views of the National Institutes of Health

\section{REFERENCES}

1. Davis SK, Liu Y, Gibbons GH. Disparities in trends of hospitalization for potentially preventable chronic conditions among African Americans during the 1990s: Implications and benchmarks. Am J Public Health 2003;93(3):447-55.

2. Spanakis EK, Golden SH. Race/ethnic difference in diabetes and diabetic complications. Current Diabetes Reports 2013;13(6):814-23.

3. Wagner EH, Sandhu N, Newton KM, McCulloch DK, Ramsey SD, Grothaus LC. Effect of improved glycemic control on health care costs and utilization. J Am Med Assoc 2001;285(2):182-9.

4. Steinsbekk A, Rygg L, Lisulo M, Rise MB, Fretheim A. Group based diabetes self-management education compared to routine treatment for people with type 2 diabetes mellitus. A systematic review with metaanalysis. BMC Health Serv Res. 2012;12(1):213.

5. Pillay J, Armstrong MJ, Butalia S, Donovan LE, Sigal RJ, Vandermeer B, et al. Behavioral programs for type 2 diabetes mellitus: a systematic review and network meta-analysis. Ann Intern Med 2015;163(11):848-60.

6. Odgers-Jewell K, Ball L, Kelly $\mathbf{J}$, Isenring $\mathbf{E}$, Reidlinger $\mathbf{D}$, Thomas $\mathbf{R}$. Effectiveness of group-based self-management education for individuals with Type 2 diabetes: a systematic review with meta-analyses and metaregression. Diabet Med 2017;34(8):1027-39.

7. Creamer J, Attridge M, Ramsden M, Cannings-John R, Hawthorne $\mathbf{K}$. Culturally appropriate health education for Type 2 diabetes in ethnic minority groups: an updated Cochrane Review of randomized controlled trials. Diabet Med 2016;33(2):169-83. https://doi.org/10.1111/dme. 12865

8. Cunningham AT, Crittendon DR, White N, Mills GD, Diaz V, LaNoue MD. The effect of diabetes self-management education on HbAlc and quality of life in African-Americans: a systematic review and metaanalysis. BMC Health Serv Res 2018;18(1):367.

9. Lynch EB, Liebman R, Ventrelle J, Keim K, Appelhans BM, Avery EF, et al. Design of the Lifestyle Improvement through Food and Exercise (LIFE) study: a randomized controlled trial of self-management of type 2 diabetes among African American patients from safety net health centers. Contemp Clin Trials 2014;39(2):246-55. https://doi.org/10.1016/j.cct. 2014.09.003

10. Lynch EB, Liebman R, Ventrelle J, Avery EF, Richardson D. A selfmanagement intervention for African Americans with comorbid diabetes and hypertension: a pilot randomized controlled trial. Prev Chronic Dis 2014;11:E90. https://doi.org/10.5888/pcd11.130349

11. Beck J, Greenwood DA, Blanton L, Bollinger ST, Butcher MK, Condon JE, et al. 2017 National standards for diabetes self-management education and support. The Diabetes Educator 2017;43(5):449-64.

12. Lynch E, Mack LJ, Karavolos K, Avery E, Liebman R, Keim KS, et al. Recruitment and baseline characteristics of participants in the Lifestyle Improvement through Food and Exercise (LIFE) study. J Health Care Poor Underserved 2017;28(1):463-86.

13. Glasgow RE, Hampson SE, Strycker LA, Ruggiero L. Personal-model beliefs and social-environmental barriers related to diabetes self-management. Diabetes Care 1997;20(4):556-61. 
14. Wolff K, Cavanaugh $\mathbf{K}$, Malone R, Hawk V, Gregory BP, Davis D, et al. The Diabetes Literacy and Numeracy Education Toolkit (DLNET): Materials to facilitate diabetes education and management in patients with low literacy and numeracy skills. Diabetes Educator 2009;35(2):233-45.

15. Wood JR, Kaminski BM, Kollman C, Beck RW, Hall CA, Yun JP, et al. Accuracy and precision of the Axis-Shield Afinion hemoglobin Alc measurement device. J Diabetes Sci Technol 2012;6(2):380-6.

16. Caskie GIL, Willis SL. Congruence of Self-Reported Medications with Pharmacy Prescription Records in Low-Income Older Adults. Gerontologist. 2004;44(2): 176-85.

17. Chiuve SE, Fung TT, Rimm EB, Hu FB, McCullough ML, Wang M, et al. Alternative dietary indices both strongly predict risk of chronic disease. J Nutr. 2012:jn. 111.157222.

18. Sasaki JE, John D, Freedson PS. Validation and comparison of ActiGraph activity monitors. J Sci Med Sport 2011;14(5):411-6.

19. Aguilar-Farias N, Brown WJ, Peeters GM. ActiGraph GT3X+ cut-points for identifying sedentary behaviour in older adults in free-living environments. J Sci Med Sport / Sports Med Aust 2014;17(3):293-9. https:// doi.org/10.1016/j.jsams.2013.07.002

20. Parmenter K , Wardle J. Development of a general nutrition knowledge questionnaire for adults. Eur J Clin Nutr 1999;53(4):298-308.

21. Wardle $\mathbf{J}$, Parmenter $\mathbf{K}$, Waller $\mathbf{J}$. Nutrition knowledge and food intake. Appetite. 2000;34(3):269-75. https://doi.org/10.1006/appe.1999.0311

22. Watts SA, Anselmo JM, Kern E. Validating the AdultCarbQuiz: A Test of Carbohydrate-Counting Knowledge for Adults With Diabetes. Diabetes Spectrum 2011;24(3):154-60. https://doi.org/10.2337/diaspect.24.3. 154

23. Morisky D, Ang A, Krousel-Wood M, Wand H. Predictive Validity of a Medication Adherence Measure for Hypertension Control. J Clin Hypertens 2008;10(5):348-54.

24. Krousel-Wood M, Islam T, Webber LS, Re R, Morisky DE, Muntner P. New medication adherence scale versus pharmacy fill rates in hypertensive seniors. Am J Manag Care 2009; 15(1):59.

25. Morisky DE, DiMatteo MR. Improving the measurement of self-reported medication nonadherence: Final response. J Clin Epidemiol 2011;64(3):258-63.

26. Morisky DE, Ang A, Krousel-Wood M, Ward HJ. Predictive validity of a medication adherence measure in an outpatient setting. J Clin Hypertens (Greenwich) 2008;10(5):348-54.

27. Kroenke K, Spitzer RL, williams JB. The PHQ-9: validity of a brief depression severity measure. J Gen Intern Med 2001;16(9):606-13.

28. Fitzgerald JT, Davis WK, Connell CM, Hess GE, Funnell MM, Hiss RG. Development and validation of the Diabetes Care Profile. Eval Health Prof 1996; 19(2):208-30.

29. Anderson RM, Fitzgerald JT, Wisdom K, Davis WK, Hiss RG. A comparison of global versus disease-specific quality-of-life measures in patients with NIDDM. Diabetes Care 1997;20(3):299-305. https://doi. org/10.2337/diacare.20.3.299
30. Fitzgerald JT, Anderson RM, Gruppen LD, Davis WK, Aman LC, Jacober SJ, et al. The reliability of the Diabetes Care Profile for African Americans. Eval Health Prof 1998;21(1):52-65.

31. Weiss BD, Mays MZ, Martz W, Castro KM, DeWalt DA, Pignone MP et al. Quick assessment of literacy in primary care: the newest vital sign. Ann Fam Med 2005;3(6):514-22. https://doi.org/10.1370/afm. 405

32. Mayer SB, Jeffreys AS, Olsen MK, McDuffie JR, Feinglos MN, Yancy W. Two diets with different haemoglobin Alc and antiglycaemic medication effects despite similar weight loss in type 2 diabetes. Diabetes Obes Metab 2014;16(1):90-3.

33. Turner R. Effect of intensive blood-glucose control with metformin on complications in overweight patients with type 2 diabetes (UKPDS 34). Lancet. 1998;352(9131):854-65.

34. AADE. AADE guidelines for the practice of diabetes self-management education and training (DSME/T). Diabetes Educator 2009;35(SUPPL. 3):85S-107S.

35. Sotos-Prieto M, Bhupathiraju SN, Mattei J, Fung TT, Li Y, Pan A, et al. Changes in diet quality scores and risk of cardiovascular disease among US men and women. Circulation. 2015:CIRCULATIONAHA. 115.017158.

36. Wang DD, Li Y, Chiuve SE, Hu FB, Willett WC. Improvements in US die helped reduce disease burden and lower premature deaths, 1999-2012; overall diet remains poor. Health Aff 2015;34(11):1916-22.

37. Cespedes EM, Hu FB, Tinker L, Rosner B, Redline S, Garcia L, et al. Multiple healthful dietary patterns and type 2 diabetes in the Women's health initiative. American journal of epidemiology. 2016:kwv241.

38. Ley SH, Pan A, Li Y, Manson JE, Willett WC, Sun Q, et al. Changes in Overall Diet Quality and Subsequent Type 2 Diabetes Risk: Three US Prospective Cohorts. Diabetes Care 2016;39(11):2011-8.

39. Laraia BA, Karter AJ, Warton EM, Schillinger D, Moffet HH, Adler N. Place matters: neighborhood deprivation and cardiometabolic risk factors in the Diabetes Study of Northern California (DISTANCE). Soc Sci Med 2012;74(7):1082-90.

40. Ludwig J, Sanbonmatsu L, Gennetian L, Adam E, Duncan GJ, Katz LF, et al. Neighborhoods, obesity, and diabetes-a randomized social experiment. N Engl J Med 2011;365(16):1509-19.

41. Gaskin DJ, Thorpe RJ, Jr., McGinty EE, Bower K, Rohde C, Young JH et al. Disparities in diabetes: the nexus of race, poverty, and place. Am J Public Health 2014;104(11):2147-55. https://doi.org/10.2105/AJPH. 2013.301420

Publisher's Note: Springer Nature remains neutral with regard to jurisdictional claims in published maps and institutional affiliations. 